\title{
Validation of cone beam computed tomography as a clinical imaging method for dentin thickness measurement in the danger zone of mandibular molars
}

\section{Validação da tomografia computadorizada de feixe cônico como um método de imagem clínico para mensuração da espessura dentinária na zona de risco de molares inferiores}

\author{
Fernanda Gomez Corrêa* \\ Claudia Bohrer Flores* \\ Flávia Kolling Marquezan ${ }^{* * *}$ \\ Gabriela Salatino Liedke \\ Gustavo Nogara Dotto***** \\ Marcia da Silva Schmitz ${ }^{* * *+}$
}

\begin{abstract}
Objective: to verify the accuracy of cone beam computed tomography (CBCT) for measuring dentin thickness in the danger zone of mandibular molars in order to validate this method to be used as a clinical auxiliary. Materials and method: dentin thickness of the distal wall of mesial canals was measured at $2 \mathrm{~mm}$ of furcation area in ten mandibular molars before and after preparation of cervical and middle thirds. CBCT (0.25 mm voxel size) and stereomicroscopy images were acquired twice for each sample. CBCT axial images and stereomicroscope images were evaluated by a calibrated examiner. Statistical analysis was performed using Mann-Whitney test in order to investigate whether CBCT images provided trusted values. Results: mean values of initial (1.23 versus $1.24 \mathrm{~mm}$ ) and final measurements ( 0.88 versus 0.87 $\mathrm{mm}$ ) obtained with, respectively, СВCT and stereomicroscope methods did not show statistical differences $(P>0.5)$. Conclusion: CBCT images provide high accuracy for measuring dentin thickness in the danger zone of mandibular molars.
\end{abstract}

Keywords: Cone beam computed tomography. Endodontics. Root canal preparation.

\section{Introduction}

Cone beam computed tomography (CBCT) is currently indicated to improve the diagnosis of complex root canal systems (RCS) ${ }^{1,2}$. However, to our knowledge, there is no specific mention regarding the evaluation of the danger zone at the furcation area, neither any study validating the use of CBCT for this purpose. The need of this investigation is justified by the high prevalence of strip perforation accidents at the furcation area, reported by several articles $^{3-6}$, suggesting that the understanding of the danger zone may be an important step during endodontic treatment planning. Preparation of the cervical and middle thirds provides countless advantages for endodontic treatment, enabling free and direct access for the entire actual working length. Additionally, it promotes greater removal of contamination at the cervical third, greater penetration of the irrigating solution, lower possibility of steps formation and fracture of the endodontic instrument, lower extrusion of necrotic debris and micro-

Me, Graduate Program in Dental Sciences, School of Dentistry, Federal University of Santa Maria (UFSM), Santa Maria, Rio Grande do Sul, Brazil. Me, Graduate Program in Dental Sciences, School of Dentistry, Federal University of Santa Maria (UFSM), Santa Maria, Rio Grande do Sul, Brazil. Me, Graduate Program in Dental Sciences, School of Dentistry, Federal University of Santa Maria (UFSM), Santa Maria, Rio Grande do Sul, Brazil. PhD, Adjunct Professor, Department of Stomatology, School of Dentistry, Federal University of Santa Maria (UFSM), Santa Maria, Rio Grande do Sul, Brazil. PhD, Associate Professor, Department of Stomatology, School of Dentistry, Federal University of Santa Maria (UFSM), Santa Maria, Rio Grande do Sul, Brazil. PhD, Associate Professor, Department of Stomatology, School of Dentistry, Federal University of Santa Maria (UFSM), Santa Maria, Rio Grande do Sul, Brazil. 
organisms to the apex, and more precise determination of the initial apical instrument length ${ }^{7,8}$.

Several methods have been used to evaluate RCS, which could assess the risk of tearing and perforation at the furcation area, such as histological sections ${ }^{9}$, serial sections ${ }^{10}$, clearing ${ }^{11}$, scanning electron microscopy ${ }^{12}$, stereomicroscope ${ }^{13}$, radiographs ${ }^{14}$, silicone impressions of the root canal ${ }^{15}$, $\mathrm{CBCT}^{16,17}$, and micro computed tomography (micro$-\mathrm{CT})^{18}$. Among clinical methods, which can be used in vivo, $\mathrm{CBCT}$ is a promising one, since it allows tridimensional evaluation ${ }^{19,20}$. For in vitro studies, both micro-CT and stereomicroscope images are used for gold standard references in RCS evaluations $^{21-23}$.

On daily clinic, CBCT scans are normally requested to settle doubts regarding the presence of strip perforations, which, sometimes, are not conspicuous only by clinical means, or to evaluate dentin thickness after root canal modeling, if the patient complains of pain or discomfort to chewing after tooth restoration ${ }^{17}$. However, no study has validated CBCT images for the danger zone investigation. Therefore, the present study aimed to investigate the accuracy of CBCT for measuring dentin thickness in the danger zone of mandibular molars, comparing the measurements performed on CBCT images to the direct measurements of dentin thickness obtained with the stereomicroscope, in order to validate this method to be used as a clinical auxiliary.

\section{Materials and method}

This investigation was approved by the Research Ethics Committee of Santa Maria Federal University (No 09686112.7.0000.5346). Teeth were provided by a tooth bank of the same institution. The sample size was estimated considering the standard deviation reported for the dentine thickness in mesial roots of mandibular molars ${ }^{13}$, the voxel size used $(0.25 \mathrm{~mm})$, a significance level of $5 \%$, and a power test of $80 \%$.

\section{Sample preparation}

Ten permanent first mandibular molars with complete root formation, measuring from 19 to 21 $\mathrm{mm}$ length ${ }^{13}$, without endodontic treatment, root fractures, and/or perforations were used. After coronal opening, the working length was determined reducing $1 \mathrm{~mm}$ after the file tip became visible at the apical foramen of the mesio buccal (MB) canal. Crown-furcation length was measured with a digital caliper (Starret 727-2001, Itu, Brazil), and the section length line was calculated by adding $2 \mathrm{~mm}$ to crown-furcation length, and marked using red nail polish (Figure 1, a).
The teeth roots were included into acrylic test tubes of $25 \mathrm{~mm}$ isolated with petroleum jelly and filled with polyester resin (Redealase, São Paulo, Brazil). Before resin polimerization, two cylindrical metallic guidewires were inserted into the tube to allow repositioning the teeth halves after sectioning (Figure 1, b). After 24 hours, specimens (resin block with the inserted tooth) were removed from the test tubes and sectioned at $2 \mathrm{~mm}$ from the furcation area using a diamond disc (Dhpro-Rhadarte, Paranaguá, Brazil) of $0.2 \mathrm{~mm}$ thickness.

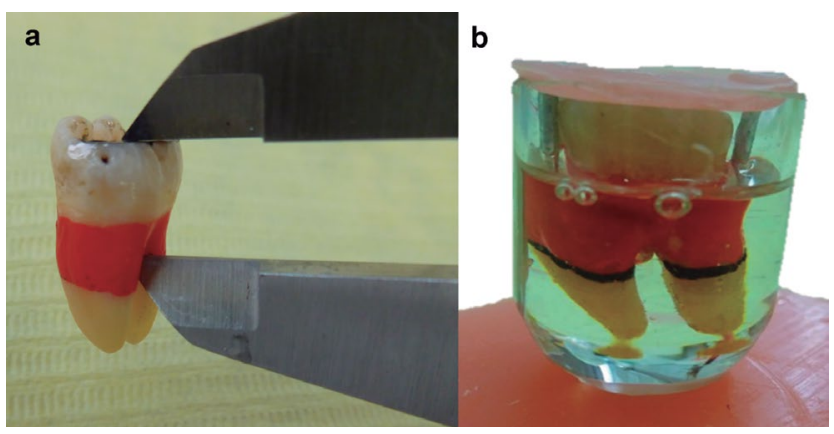

Figure 1 - Sequence used for sample preparation

Notes: a) determination of the distance between crown and furcation with a caliper; b) tooth included in the acrylic muffle with the section line, $2 \mathrm{~mm}$ bellow furcation, determined.

Source: authors.

\section{CBCT acquisitions}

In order standardize the position of the teeth for CBCT acquisitions before and after preparation, the specimens were enclosed into specific cocoons in a plaster guidewire. CBCT scans were taken with an i-Cat unit (Imaging Sciences International, LLC, Hatfield, PA), field of view (FOV) of $16 \mathrm{~cm}$ (diameter) $\mathrm{x} 8 \mathrm{~cm}$ (height), with a $0.25 \mathrm{~mm}$ voxel size protocol ( $120 \mathrm{kVp}, 5 \mathrm{mAs}$, and $26 \mathrm{~s})$. Images were stored on a computer for subsequent analysis. The same protocol of CBCT acquisition was repeated after the cervical and middle thirds preparation.

\section{Stereomicroscope images}

Specimens' halves were separated, and the coronal portion was placed so that the canal at the furcation area was facing the stereomicroscope (Stereo Discovery V20, Carl Zeiss, Germany) objective, allowing the measurements at the danger zone. A picture with 40x magnification was taken and stored on a computer for subsequent analysis. The same protocol for stereomicroscope images acquisition was repeated after the cervical and middle thirds preparation.

\section{Cervical and middle thirds preparation}

Cervical and middle thirds of the teeth were prepared using CPDrill ${ }^{\mathrm{TM}}$ (Helse Indústria e Comércio Ltda., Santa Rosa, Brazil) instruments. In 
order to ensure that the preparation was performed at the region of interest (i. e., $2 \mathrm{~mm}$ below bifurcation), the minimum length of drill penetration was determined based on the working length. Drilling was performed by the same trained operator, using a TC 3000 motor (Nouvag, Goldach, Switzerland) at $10.000 \mathrm{rpm} / \mathrm{min}$.

After preparation, the specimens were re-enclosed into the plaster guidewires for the second CBCT scan. For the second stereomicroscope image, the coronal portion was separated and evaluated using the same methodology described before.

\section{Image evaluation}

One calibrated examiner assessed all CBCT and stereomicroscope images. The distance between the distal wall of the MB root canal to the furcation area (corresponding to the danger zone thickness) was measured.

CBCT images were evaluated with i-CAT visionTM software (Imaging Sciences International, LLC, Hatfield, USA). Using the multiplanar mode, the tooth was oriented with its long axis perpendicular to the ground, a line measuring $2 \mathrm{~mm}$ was traced on the coronal plane, and the axial plane was oriented bellow that line so the dentin thickness measurements at the danger zone were performed (Figure 2, a). Images acquired before and after the cervical and middle thirds preparation were evaluated at the same time, using two computers, to ensure standardization ${ }^{16}$.

Stereomicroscope images were measured using Image Tool software, version 3.0 (University of Texas Health Science Center, San Antonio, USA) (Figure $2, \mathrm{~b}$ ).

Three measurements were performed for each method (CBCT axial images and stereomicroscope images), and the mean among these measurements were used for subsequent analysis.

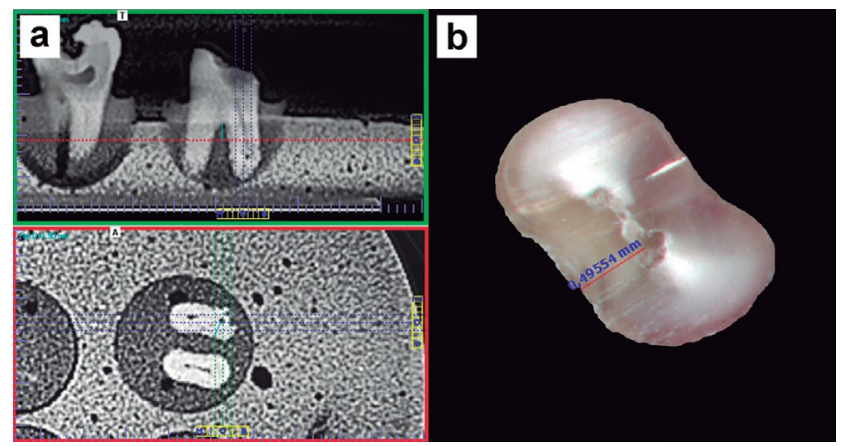

Figure 2 - Sample evaluation

Notes: a) coronal and axial planes orientation for tomographic measurement; b) stereomicroscope measurement in the danger zone of the mesio buccal canal.

Source: authors.

\section{Statistical analysis}

Statistical analysis was performed with Microsoft Excel 2010 software (Microsoft Corp., Redmond, WA, USA), and STATA 13 software (Philadelphia, PA, USA). The level of statistical significance was $P<0.05$.

Data was first analyzed using Shapiro-Wilk test to assess normality. In view of the non-normal distribution of data, a non-parametric Mann-Whitney test for independent samples was used to compare both methods.

\section{Results}

Table 1 shows the dentin thickness (in $\mathrm{mm}$ ) obtained with CBCT and stereomicroscope images. Mean values between methods were not statistically significant different $(P>0.5)$ both before and after the cervical and middle thirds preparation.

\begin{tabular}{|c|c|c|c|c|}
\hline \multirow{2}{*}{ Specimen } & \multicolumn{2}{|c|}{ Before } & \multicolumn{2}{|c|}{ After } \\
\hline & CBCT & stereo & CBCT & Stereo \\
\hline 1 & 0.95 & 0.89 & 0.76 & 0.59 \\
\hline 2 & 1.30 & 1.35 & 0.86 & 0.92 \\
\hline 3 & 1.06 & 1.02 & 0.75 & 0.74 \\
\hline 4 & 1.32 & 1.38 & 0.86 & 0.88 \\
\hline 5 & 1.43 & 1.38 & 0.94 & 0.99 \\
\hline 6 & 1.82 & 1.79 & 1.39 & 1.37 \\
\hline 7 & 0.97 & 0.93 & 0.74 & 0.70 \\
\hline 8 & 1.42 & 1.44 & 0.96 & 0.98 \\
\hline 9 & 1.02 & 1.02 & 0.71 & 0.70 \\
\hline 10 & 1 & 1.02 & 0.79 & 0.82 \\
\hline Mean (SD) & $1.23(0.28)$ & $1.22(0.29)$ & $0.88(0.20)$ & $0.87(0.22)$ \\
\hline $\mathrm{P}$ & \multicolumn{2}{|c|}{0.9698} & \multicolumn{2}{|c|}{0.8798} \\
\hline
\end{tabular}

Source: present research.

\section{Discussion}

The present study aimed to evaluate the accuracy of CBCT for the assessment of dentin thickness in the danger zone of mandibular molars, which had not been throughout validated. Clinically, for many years, radiographic examination was the only available method. However, although widely used, these images have some drawbacks, such as distortions and/or amplifications, due to errors in the horizontal and/or vertical angles of X-ray, and overlapping of anatomic structures, which may influence imaging interpretation and diagnostic accuracy. In order to overcome these limitations, CBCT images are increasingly being used in endodontics ${ }^{1}$. 
In clinical practice, CBCT has been shown to be useful in the differential diagnosis among endodontic pathologies, diagnosis of alveolar and root fractures, evaluation of root canal morphology, analysis of internal and external resorption, pre-surgical endodontic planning, and detection of bone lesions ${ }^{1,17,24,25}$. Additionally, CBCT provides good cost-benefit for both patients and professionals, mostly due to two factors. First, patients are exposed to reduced doses of radiation ${ }^{26}$. Second, CBCT images allow the dentist to obtain submillimeter images with high-quality spatial resolution in a short time of acquisition and multiple possibilities of virtual assessment of maxillary regions and printed images in a rate of $1: 1^{26}$.

There is evidence that $\mathrm{CBCT}$ is valuable in the investigation of the exact location access, anatomy and exploration of the root canal system ${ }^{27,28}$, measuring dentin thickness, and evaluation of root canal modeling before and after instrumentation ${ }^{16,29}$. However, no study has compared CBCT images, taking care on sample acquisition and evaluation, to a gold standard method. A study performed by Flores et al. ${ }^{16}$ (2012) sugested that CBCT was an effective method to measure dentin thickness at the danger zone. Nevertheless, the former study does not have a gold standard. Therefore, the present study compared the measurements performed on CBCT images to stereomicroscope images (direct measurement). The measurements found in this study corroborate the results of other studies using diverse methodologies to assess the danger zone $2 \mathrm{~mm}$ below furcation area ${ }^{13,16,30,31}$. The absence of differences between the two methods suggests that CBCT is an imaging diagnostic tool that may be used clinically (in patients), allowing professionals to control the risk of tearing due to excessive wear during root canal preparation.

Some limitations of the present study should be considered: the evaluated teeth had no source of noise and artefacts, such as patient motion or dense materials ${ }^{32}$. Images were evaluated by only one examiner; however, this attempt was made to restrict the source of error to the imaging methods, and not to the variance among different examiners. Besides, only one CBCT unit (i-Cat) and one voxel size $(0,25 \mathrm{~mm})$ was tested; nevertheless, considering the absence of differences between the methods using this acquisition protocol, probably smaller voxel sizes would also allow to investigate the danger zone thickness.

\section{Conclusion}

Axial CBCT images provide high accuracy for measuring dentin thickness in the danger zone of permanent first mandibular molars, and so can be employed as an adjunct clinical imaging method.

\section{Resumo}

Objetivo: avaliar a acurácia da tomografia computadorizada de feixe cônico (TCFC) para mensurar a espessura dentinária na zona de risco de molares inferiores e validar este método, a fim de usá-lo como um auxiliar clínico. Materiais e método: a espessura dentinária da parede distal dos canais mesiais foi medida a $2 \mathrm{~mm}$ da área de furca em dez molares inferiores, antes e após a preparação dos terços médio e cervical. Foram adquiridas imagens por TCFC (tamanho do voxel de 0,25 mm) e estereomicroscopia. Um examinador treinado e calibrado avaliou as tomografias no plano axial e as imagens de estereomicroscopia. A análise estatística foi realizada com o teste Mann-Whitney, para verificar se as imagens tomográficas forneceram valores comparáveis à estereomicroscopia. Resultados: a média dos valores obtidos, respectivamente, após as mensurações iniciais $(1,23$ versus $1,24 \mathrm{~mm})$ e finais $(0,88$ versus $0,87 \mathrm{~mm})$ das imagens de TCFC e estereomicroscopia não mostraram diferença estatisticamente significativa entre os métodos $(P>0,5)$. Conclusão: a TCFC produz imagens acuradas para a mensuração da espessura dentinária na zona de risco de molares inferiores.

Palavras-chave: Endodontia. Preparo de canal radicular. Tomografia computadorizada de feixe cônico.

\section{References}

1. Patel S, Durack C, Abella F, Roig M, Shemesh H, Lambrechts P, et al. European Society of Endodontology position statement: the use of CBCT in endodontics. Int Endod J 2014; 47(6):502-4.

2. Al-Fouzan KS, Ounis HF, Merdad K, Al-Hezaimi K. Incidence of canal systems in the mesio-buccal roots of maxillary first and second molars in Saudi Arabian population. Aust Endod J 2013; 39(3):98-101.

3. Akbar I. Radiographic study of the problems and failures of endodontic treatment. Int J Health Sci (Qassim) 2015; 9(2):111-8.

4. Pettiette MT, Metzger Z, Phillips C, Trope M. Endodontic complications of root canal therapy performed by dental students with stainless-steel K-files and nickel-titanium hand files. J Endod 1999; 25(4):230-4.

5. Eghbal MJ, Fazlyab M, Asgary S. Repair of a strip perforation with calcium-enriched mixture cement: a case report. Iran Endod J 2014; 9(3):225-8.

6. Froughreyhani M, Salem Milani A, Barakatein B, Shiezadeh V. Treatment of Strip Perforation Using Root MTA: A Case Report. Iran Endod J 2013; 8(2):80-3.

7. Schmitz Mda S, Santos R, Capelli A, Jacobovitz M, Spano JC, Pecora JD. Influence of cervical preflaring on determination of apical file size in mandibular molars: SEM analysis. Braz Dent J 2008; 19(3):245-51.

8. Borges AH, Pereira TM, Porto AN, de Araujo Estrela CR, Miranda Pedro FL, Aranha AM, et al. The Influence of Cervical Preflaring on the Amount of Apically Extruded Debris after Root Canal Preparation Using Different Instrumentation Systems. J Endod 2016; 42(3):465-9.

9. Walton RE. Histologic evaluation of different methods of enlarging the pulp canal space. J Endod 1976; 2(10):304-11. 
10. Tabrizizadeh M, Reuben J, Khalesi M, Mousavinasab M, Ezabadi MG. Evaluation of radicular dentin thickness of danger zone in mandibular first molars. J Dent (Tehran) 2010; 7(4):196-9.

11. Peiris HR, Pitakotuwage TN, Takahashi M, Sasaki K, Kanazawa E. Root canal morphology of mandibular permanent molars at different ages. Int Endod J 2008; 41(10):828-35.

12. Samiei M, Pakdel SM, Rikhtegaran S, Shakoei S, Ebrahimpour D, Taghavi P. Scanning electron microscopy comparison of the cleaning efficacy of a root canal system by Nd:YAG laser and rotary instruments. Microsc Microanal 2014; 20(4):1240-5.

13. Sauaia TS, Gomes BP, Pinheiro ET, Zaia AA, Ferraz CC, Souza-Filho FJ, et al. Thickness of dentine in mesial roots of mandibular molars with different lengths. Int Endod J 2010; 43(7):555-9.

14. Southard DW, Oswald RJ, Natkin E. Instrumentation of curved molar root canals with the Roane technique. J Endod 1987; 13(10):479-89.

15. Abou-Rass M, Jastrab RJ. The use of rotary instruments as auxiliary aids to root canal preparation of molars. J Endod 1982; 8(2):78-82.

16. Flores CB, Machado P, Montagner F, Gomes BPFA, Dotto GN, Schmitz MS. A methodology to standardize the evaluation of root canal instrumentation using cone beam computed tomography. Braz J Oral Sci 2012; 11(2):84-7.

17. Haghanifar S, Moudi E, Mesgarani A, Bijani A, Abbaszadeh N. A comparative study of cone-beam computed tomography and digital periapical radiography in detecting mandibular molars root perforations. Imaging Sci Dent 2014; 44(2):115-9.

18. Moura-Netto C, Palo RM, Camargo CH, Pameijer CH, Bardauil MR. Micro-CT assessment of two different endodontic preparation systems. Braz Oral Res 2013; 27(1):26-30.

19. Vizzotto MB, Silveira PF, Arus NA, Montagner F, Gomes BP, da Silveira HE. CBCT for the assessment of second mesiobuccal (MB2) canals in maxillary molar teeth: effect of voxel size and presence of root filling. Int Endod J 2013; 46(9):870-6.

20. Guedes OA, da Costa MV, Dorileo MC, de Oliveira HF, Pedro FL, Bandeca MC, et al. Detection of Procedural Errors during Root Canal Instrumentation using Cone Beam Computed Tomography. J Int Oral Health 2015; 7(3):28-32.

21. Acar B, Kamburoglu K, Tatar I, Arikan V, Celik HH, Yuksel $\mathrm{S}$, et al. Comparison of micro-computerized tomography and cone-beam computerized tomography in the detection of accessory canals in primary molars. Imaging Sci Dent 2015; 45(4):205-11.

22. Kumari MR, Krishnaswamy MM. Comparative Analysis of Crack Propagation in Roots with Hand and Rotary Instrumentation of the Root Canal -An Ex-vivo Study. J Clin Diagn Res 2016; 10(7):ZC16-9.

23. Shahravan A, Rekabi A, Shahabi H, Ashuri R, Mirzazadeh A, Rad M, et al. A digital stereomicroscopic study of the furcation wall thickness of mesiobuccal roots of maxillary first and second molars. Iran Endod J 2010; 5(2):88-92.

24. Lababidi EA. Discuss the impact technological advances in equipment and materials have made on the delivery and outcome of endodontic treatment. Aust Endod J 2013; 39(3):92-7.

25. Taramsari M, Kajan ZD, Bashirzadeh P, Salamat F. Comparison of high-resolution and standard zoom imaging modes in cone beam computed tomography for detection of longitudinal root fracture: An in vitro study. Imaging Sci Dent 2013; 43(3):171-7.

26. Scarfe WC, Farman AG. What is cone-beam CT and how does it work? Dent Clin North Am 2008; 52(4):707-30.
27. Michetti J, Maret D, Mallet JP, Diemer F. Validation of cone beam computed tomography as a tool to explore root canal anatomy. J Endod 2010; 36(7):1187-90.

28. Patel S, Kanagasingam S, Mannocci F. Cone beam computed tomography (CBCT) in endodontics. Dent Update 2010; 37(6):373-9.

29. Sanfelice CM, da Costa FB, Reis So MV, Vier-Pelisser F, Souza Bier CA, Grecca FS. Effects of four instruments on coronal pre-enlargement by using cone beam computed tomography. J Endod 2010; 36(5):858-61.

30. Flores CB, Montagner F, Gomes BP, Dotto GN, da Silva Schmitz M. Comparative assessment of the effects of Gates-Glidden, Largo, LA-Axxess, and New Brazilian Drill CPdrill on coronal pre-enlargement: cone-beam computed tomographic analysis. J Endod 2014; 40(4):571-4.

31. Sousa K, Andrade-Junior CV, Silva JM, Duarte MA, De-Deus G, Silva EJ. Comparison of the effects of TripleGates and Gates-Glidden burs on cervical dentin thickness and root canal area by using cone beam computed tomography. $\mathrm{J}$ Appl Oral Sci 2015; 23(2):164-8.

32. Schulze R, Heil U, Gross D, Bruellmann DD, Dranischnikow E, Schwanecke U, et al. Artefacts in CBCT: a review. Dentomaxillofac Radiol 2011; 40(5):265-73.

\section{Corresponding author:}

Gabriela Salatino Liedke

Oral Radiology, Department of Stomatology,

Santa Maria Federal University

Marechal Floriano Peixoto, 1184

97015-372, Santa Maria, Rio Grande do Sul, Brazil

Phones: (+55) (55) 3220-9270

(+55) (55) 3220-9204

(+55) (51) 99817-4624

E-mail: gabriela.liedke@ufsm.br

Recebido: 08/01/17. Aceito: 22/02/18. 